\title{
Exploration and Research on the Teaching Mode of Landscape Design under the Background of Smart City
}

\author{
Wenjun Wang \\ City College of WUST, Wuhan, China \\ 15827425957@163.com
}

Keywords: Smart City; information era; Landscape Design

\begin{abstract}
Under the background of smart city, this paper explores and studies the teaching mode of existing landscape design courses. Landscape design is an interdisciplinary subject. Although it has been developed for decades in China, it has many limitations in the teaching mode. In the Internet era, smart cities make full use of information technology to serve urban construction, make urban life more convenient and intelligent, and realize sustainable urban development. Landscape design and smart city share the same goal, and strive to create a better living environment and promote urban green, harmonious and sustainable development.
\end{abstract}

\section{Introduction}

This article revolves around landscape design course teaching pattern reform, to improve the landscape design course teaching effect as the goal, to the time background of wisdom city as the breakthrough point, through teaching, practice, discussion and the project type teaching in a variety of ways, such as landscape design teaching time background, the students master the core principles of landscape design, landscape design in the design and practical, to wisdom urban construction.

The teaching mode of landscape design can first make full use of the information technology in smart cities to improve the traditional teaching mode, adjust the proportion of design theory and case analysis, and get rid of the ancient landscape design. Secondly, it will increase investigation, experiment and practice activities to help students understand the principles of ecological landscape design and get rid of the flashy landscape design. Finally, project teaching can be introduced at the junction of smart city and landscape design to apply the knowledge and get rid of the paper-based landscape design.

Only a few years have passed since the proposal of smart city was established. There are few papers exploring the intersection of smart city and landscape design as the teaching mode of landscape design. At present, most universities in China are relatively conservative in the teaching mode of landscape design courses, which is mainly reflected in the following aspects: more teachers teach, less students discuss; Explain the principle more, analyse the principle less; There are many traditional and classical cases, but few modern green ecology cases. More lectures, less practice, and so on.

\section{Current situation and problems}

Landscape design is a very comprehensive and applied subject, which has the following limitations in the traditional teaching mode and teaching conditions:

The teaching model is antiquated. The main teaching mode is teachers teaching and students receiving passively. The classroom is relatively dull, teaching effect is hard to assure.

Teaching theory is divorced from social practice. For such a practical course of landscape design, too much emphasis on the teaching of theories has limited help for the improvement of practical design. In addition, the explanation of theories, principles and design standards in the teaching process is more focused on "explanation" rather than "solution", that is, the analysis of principles is less.

The teaching environment is unitary. The empty theoretical knowledge is not combined with practice, so it is difficult to have a deeper understanding of these theoretical knowledge, and the 
application of them in design is just a manual application without the key. The proportion of practice, experiment and investigation should be adjusted.

\section{Solutions}

Teaching form. The reform of traditional teaching mode combined with the information technology of smart city to carry out abundant teaching forms: flipped classroom, micro class, mooc and other forms are helpful to improve students' learning interest and efficiency. Weaken the indoctrination of theoretical dogma and eliminate the old knowledge points. Combine the concrete theory with the example to make a thorough and interpretation to help students understand the dull and difficult theoretical knowledge. At the same time, the program presentation and discussion are added. Excellent designers not only need innovative thinking ability and hands-on ability, but also the expression ability. In the process of presentation and discussion, they should revise, deepen and improve the design program, so as to improve the comprehensive ability of students.

Landscape architecture is a highly comprehensive application subject, which is a combination of landscape architecture, landscape architecture, urban planning and environmental art. It has a high degree of complexity, and has a indirect and profound influence on the improvement of urban management. Furthermore, from the perspective of landscape development, smart cities will pay more attention to people-oriented thoughts, urban functions and urban management level. Therefore, this requires our city managers and designers, not only to use perceptual eyes to see the wisdom of the urban construction, more scientific and rational way to observe and study of urban inner and outer space environment and the existing problems, and then using the advanced science and technology, effective methods to guide the wisdom of city construction, to point with surface, deepen the details, constantly lift raw intelligence management level of the city.

The innovation ability. Combined with smart city related projects, such as sponge city establishment, street center park construction, vertical greening, roof garden design, rainwater collection system, intelligent car park design, etc., to conduct project type teaching. Make full analysis of relevant cases at home and abroad before the project teaching to help students understand the design principles. In the process of practice, students are allowed to discover specific problems in the process of landscape design, discuss and issue specific solutions, and organically combine theory with practice. Avoid an armchair design.

At present, many countries and governments around the world are stepping up research and actively guiding the development of smart cities. In China, many cities also regard promoting smart city construction as an important opportunity to develop strategic emerging industries, improve urban operation efficiency and public service level, and realize leapfrog development of cities. They have put forward the development direction of smart city and embarked on future planning and construction. Experts predict that in the next 20 to 30 years, the smart city will integrate ecology, intelligence, digitization and information, and take the coordinated, low-carbon, green and safe linkage development path. Compared with the comprehensive development of smart cities, the garden landscape is more towards diversification, standardization, specialization, integration of architecture and garden landscape, and then in line with the smart city under the theme of people-oriented and ecological priority. From the perspective of long-term development, with the continuous improvement of intelligent and information-based living standards, attention is paid to intelligence and technology, innovation and sharing, information and culture, ecology and sustainability. How to create a truly livable living environment is the garden landscape and the future development of smart city for people to expect.

As for the combination of smart city construction and garden landscape, both of them are building space, both of them are aiming at the same goal and creating a beautiful living environment. The essential attributes of coordination and service, construction and optimization exist in both of the internal development laws. In the process of the development of smart cities, we need to view problems from the perspective of connection, control them as a whole, create the integration of smart cities and landscape design, and give full play to their functions and attributes. As one of the most effective participants, landscape designers need to step in ahead of time, 
communicate with urban planning departments and work together. Starting from the use function of landscape design, the details of planning and design, ecological environment requirements and intelligent system transformation are gradually upgraded and improved to form an integrated system and overall design concept. Through early collaboration and cooperation, designers and planners to explore out a meet the requirements of the integration of multilateral mechanism and effective operation way, effective mining city's unique resources, integrate the and urban landscape and architecture, landscape, vertical development the urban spatial structure and function, set up a new multiple order, to realize the integration of the urban landscape and intelligence development.

Practice. In traditional teaching mode, the content of practice is relatively few, and the absence of practice makes the effect of teaching discounted. Therefore, it is necessary to carry out abundant practical contents. The courses of landscape design cover a wide range of aspects, including planning, ecology, plants, geography, etc., and the investigation, experiment and practice of different topics have twice the result for students to master design theories and methods with half the effort. For example, I conducted investigation activities on different topics such as square, park, community, plant and waterscape, completed the investigation report, and analyzed the objects of investigation based on actual cases at home and abroad, and put forward constructive Suggestions. In the process of various practices, help students to establish a complete knowledge system, the early learning content of a systematic summary.

Nowadays, the construction of smart city and the design of garden landscape all advocate digitalization. With the development of $3 \mathrm{~S}$ technology, GIS, RS and GPS have become the two to acquire data and analyze data mutually, so as to integrate multiple data, improve the precision of image data interpretation, and make the decision-making and design process more scientific and standard. In the motor vehicle-oriented urban landscape planning project, Arkansas in the United States, the design focuses on the transformation of urban public space, in the hope of reshaping the local agricultural landscape and reclaiming farmlands. Policymakers in remote sensing image interpretation, which based on the data of land type with big data as the core support, all the city's resources and digital system, integration of quantitative models, landscape index, public participation and so on the many kinds of data, using the data of $3 \mathrm{~s}$ with other data, the comprehensive reflection of the characteristics of urban structure and landscape types, after transforming the city space is more reasonable and convenient, has a strong accessibility.

Another basic feature of garden landscape and smart city is intelligence of information. Smart city can effectively integrate intelligent processing and deep computing capacity, and realize intelligent connection and coordination among extensive data through information processing, so as to create an efficient smart city. Compared with smart city, the connection between garden landscape and smart city lies in the application of intelligent technology and information. Intelligent analysis, voice control technology, remote management software, FDR sensor system technology and other aspects of landscape architecture, plant planting management, waterscape and lighting technology are available. As Toronto, Canada, with the ultimate goal of building a smart city, smart new city plans to use information and intelligent collaborative technologies, from building, transportation, urban space, ecological environment, clean energy and other aspects, to provide citizens with comfortable use and reasonable planning of smart city space. At the same time, through the voice control technology, FDR system, urban intelligent technology such as remote information management and monitoring, combining the analysis data, provide citizens with a good sunshine, ventilation and other conditions, to reduce the noise, reduces the harmful gas suction capacity, builds a information, points out the city space and living environment.

\section{Conclusion}

The garden landscape, as an important carrier of smart city image, plays an important role in displaying the city's overall features and building a livable environment. By consulting and summarizing relevant data and analyzing and interpreting related concepts of smart city and garden landscape comprehensively, this paper believes that garden landscape is an important part of smart city and an important part of smart city, which is closely connected with smart city. Landscape can 
not only affect the development and construction of smart city, but also be closely related to the realization of smart city. It can be said that it is inseparable and indispensable. From the perspective of different stages of development and planning, the combination of smart city and garden landscape can well realize information exchange, save resources, achieve ecological efficiency, reduce management cost, and play an important role as a carrier for urban construction and development. This paper starts from the relationship and commonality between landscape and smart city construction, integrates the core values and contents of landscape and smart city, and probes into the exploration and innovation of the teaching mode of landscape courses.

\section{Acknowledgement}

The research topic of City College of WUST 2018, Exploration and Research on the Teaching Mode of Landscape Design Under the Background of Smart City. Item number:2018CYYBJY013

\section{References}

[1] X. O. Du: The Design and Study of the Urban Complex Under the Smart Cities(MS., Harbin Institute of Technology, China 2014), p.44.

[2] M. J. Li, W. Zhang: Architecture \& Culture, Vol.06(2018), p.120.

[3] X. Luo: Urban Furniture Design Based on the Application of Intelligent Technology for Example Taking the Design of Urban Landscape Flower Box(MS., Southwest Jiaotong University, China 2014), p.63.

[4] W. T. Lu: Electronic Test, Vol.11(2018), p.14.

[5] Y.B.Chen: Green Campus (China Architecture \& Building Press, China 2012), p.86.

[6] K.J.Yu, L.Li: Journal of Liaoning University of Technology(Social Science Edition), Vol.01(2016), p.81.

[7] Sun Xuehen. Planning and Design of Plant Landscape [M].The first edition. Beijing: China Forestry Publishing House, 2012.

[8] P. Tu, L. Chen: Think Tank of Science \& Technology, Vol.08(2013), p.66.

[9] X. F. Yu, Z. C. Luo: Urban Management Science \& Technology, Vol.03(2016) , p.29.

[10]P. Liu: Smart City Mobile Terminal Interactive Interface Research Based on Semiotics(D., Wuhan University, China 2014), p.143.

[11]Clare Cooper, Carolyn Francis: People Places Design Guidelines for Urban Open Space (China Architecture \& Building Press, China 2001), p.183.

[12] X.M. Wang: Roof Garden Design and Case Study (Phoenix Science Press, China 2013), p.130. 